\title{
A Comparison of the Mathematical Performance of Mature Students and Traditional Students Over a 10-Year Period
}

\author{
Fiona Faulkner \\ Technological University Dublin, fiona.faulkner@tudublin.ie \\ Olivia Fitzmaurice \\ University of Limerick \\ Olivia Hannigan \\ University of Limerick
}

Follow this and additional works at: https://arrow.tudublin.ie/ltcart

Part of the Education Commons

\section{Recommended Citation}

Faulkner, F., Fitzmaurice, O. \& Hannigan, A. (2016). A comparison of the mathematical performance of mature students and traditional students over a 10-year period. Irish Educational Studies, vol. 35, no. 4. doi.org/10.1080/03323315.2016.1229208

This Article is brought to you for free and open access by the Learning Teaching \& Assessment at ARROW@TU Dublin. It has been accepted for inclusion in Articles by an authorized administrator of ARROW@TU Dublin. For more information, please contact arrow.admin@tudublin.ie, aisling.coyne@tudublin.ie, gerard.connolly@tudublin.ie.

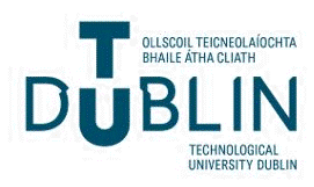




\title{
REVIEW
}

\section{A comparison of the mathematical performance of mature students and traditional students over a 10-year period}

\author{
Fiona Faulkner $^{\mathrm{a} *}$, Olivia Fitzmaurice ${ }^{\mathrm{b}}$ and Ailish Hannigan ${ }^{\mathrm{c}}$ \\ ${ }^{a}$ Hospitality and Tourism, Dublin Institute of Technology, Dublin, Ireland; ${ }^{b}$ Mathematics and \\ Statisitcs, University of Limerick, Limerick, Ireland; ${ }^{c}$ Graduate Entry Medical School, \\ University of Limerick, Limerick, Ireland
}

(Received 22 May 2015; accepted 23 June 2016)

\begin{abstract}
Every student who enrols in a degree programme involving service mathematics in the University of Limerick in Ireland is given a mathematics diagnostic test. The diagnostic test was developed due to mathematics lecturers' anxiety regarding students' mathematical competency levels. Students receive the 40 question paper-based test in their first service mathematics lecture without prior notification. Initial analysis of students' work revealed that many students were having difficulties with basic algebra and arithmetic in particular [Gill, O. 2006. "What Counts as Service Mathematics? An Investigation into the 'Mathematics Problem' in Ireland." $\mathrm{PhD}$ diss., University of Limerick]. Further research highlighted the significant decline in diagnostic test performance and the changing profile of service mathematics students between 1998 and 2008 [Faulkner, Fiona, Ailish Hannigan, and Olivia Gill. 2010. "Trends in the Mathematical Competency of University Entrants in Ireland by Leaving Certificate Mathematics Grade." Teaching Mathematics and Its Applications 29 (2): 76-93]. One of the most notable changes to the student profile over time was the increase in mature students (non-standard students) entering service mathematics programmes. Although non-standard students had a lower mean performance in the diagnostic test, they were found to have a higher mean performance in some cases in service mathematics compared to standard students. This paper explores some of the possible reasons for such findings.
\end{abstract}

Keywords: mathematics problem; mature students; learning styles; declining mathematical standards; diagnostic testing

\section{Introduction}

Many third-level institutions, in Ireland and abroad, have introduced mathematics diagnostic testing for beginning undergraduates in an attempt to identify initial weaknesses in basic mathematics skills that students may have (Tall and Razali 1993; Edwards 1995, 1996; Hunt and Lawson 1996, 1997; Todd 2001; Engineering Council 2002; Malcolm and McCoy 2007; Faulkner, Hannigan, and Gill 2010; Gill et al. 2010; Treacy and Faulkner 2015). One such institution is the University of Limerick (UL) in Ireland which introduced diagnostic testing in 1997 in an attempt to identify students who may be at risk of failing end-of-semester mathematics examinations. An analysis of the diagnostic testing results has shown a significant decline in basic mathematical competency

\footnotetext{
*Corresponding author. Email: fiona.faulkner@dit.ie 
levels over time (Gill 2006; Faulkner, Hannigan, and Gill 2010; Treacy and Faulkner 2015). In addition to this, research has been carried out which examined the relationship between a students' initial mathematical performance upon entry to UL (i.e. their performance in the diagnostic test) and their performance in end-of-term service mathematics modules. This paper outlines how students' performances in both of these examinations relate to each other, how performance has changed over time and in particular examines the performance of non-standard students ${ }^{1}$ in each examination (Faulkner, Hannigan, and Gill 2010).

\section{Background to the study}

\subsection{The $U L$}

The UL is a higher education institution based in the south of Ireland. It is the largest provider of second-level teacher education in the country with a primary focus on Science and Technology subjects (Sahlberg 2012). The institution is currently organised into faculties, the largest of which is the Science and Engineering faculty consisting of 10 different departments, including the Department of Mathematics and Statistics. One of the roles of the Department of Mathematics and Statistics is to support its client departments (Science, Technology, Business, Computers and Engineering) by delivering 'service mathematics' modules to them. Service mathematics modules are generally delivered to degree programmes where mathematics is needed but is not the main focus of the degree. Two separate service mathematics groups in UL form the focus of the research detailed in this paper: Science and Technology students. The number of students enrolling in programmes in which Science and Technology mathematics are required increased significantly over the course of this research (i.e. between 1998 and 2008). In 1998 there were 202 and 305 students enrolled in Science and Technology mathematics, respectively, which rose to 303 and 374 in 2008 (Faulkner, Hannigan, and Fitzmaurice 2014). The increased number of students within these service mathematics cohorts is due in part to the increase in standard students and also due to the increased proportion of non-standard students entering UL, which went from $0.3 \%$ to $9.4 \%$ in Technology mathematics and from $1.5 \%$ to $6.9 \%$ in Science mathematics (Table 1) (Faulkner 2012). It should be noted at this stage that many Science and Technology students are required to study mathematics beyond

Table 1. Breakdown of student demographics in Technology and Science mathematics (1998 and 2008).

\begin{tabular}{|c|c|c|c|c|}
\hline \multirow[t]{2}{*}{ Year } & 1998 & 2008 & 1998 & 2008 \\
\hline & \multicolumn{2}{|c|}{$\begin{array}{l}\text { Technology } \\
\text { mathematics }\end{array}$} & \multicolumn{2}{|c|}{ Science mathematics } \\
\hline Standard students & $\begin{array}{l}304 \\
(99.7 \%)\end{array}$ & $\begin{array}{l}339 \\
(90.6 \%)\end{array}$ & $\begin{array}{l}199 \\
(98.5 \%)\end{array}$ & $\begin{array}{l}282 \\
(93.1 \%)\end{array}$ \\
\hline Leaving Certificate Higher level & $\begin{array}{l}125 \\
(41.0 \%)\end{array}$ & $\begin{array}{l}124 \\
(33.2 \%)\end{array}$ & $\begin{array}{l}112 \\
(55.4 \%)\end{array}$ & $\begin{array}{l}115 \\
(38.0 \%)\end{array}$ \\
\hline Leaving Certificate Ordinary level & $\begin{array}{l}179 \\
(58.7 \%)\end{array}$ & $\begin{array}{l}215 \\
(57.5 \%)\end{array}$ & $\begin{array}{l}87 \\
(43.1 \%)\end{array}$ & $\begin{array}{l}167 \\
(55.1 \%)\end{array}$ \\
\hline Non-standard students & $\begin{array}{l}1 \\
(0.3 \%)\end{array}$ & $\begin{array}{l}35 \\
(9.4 \%)\end{array}$ & $\begin{array}{l}3 \\
(1.5 \%)\end{array}$ & $\begin{array}{l}21 \\
(6.9 \%)\end{array}$ \\
\hline
\end{tabular}


first year; however, this paper focusses solely on their first year mathematics performance as all students in these two service mathematics groups are required to take mathematics in first year. The years over which this research was conducted (1998-2008) are significant in the context of mathematics education in Ireland as they allow us to get a clear picture of the basic mathematical skills of beginning undergraduates in the years directly preceding the introduction of a new mathematics curriculum at second level entitled Project Maths.

\subsection{Diagnostic testing in $U L$}

The catalyst for the initial implementation of diagnostic testing in UL in 1997 was mathematics lecturers' concerns regarding students' basic mathematical competency levels on entry to UL. The test which consists of 40 questions was deemed a suitable tool to identify whether students had mathematical weaknesses on entry and to direct them to get mathematics support if this was found to be the case (Faulkner, Hannigan, and Gill 2010; Faulkner, Hannigan, and Fitzmaurice 2014; Treacy and Faulkner 2015).

During the lifespan of this research (1998-2008) ${ }^{2}$ almost 6000 students took the diagnostic test in UL. This number increased to almost 10,000 by the close of diagnostic testing in 2014 (Treacy and Faulkner 2015). Students are asked to complete the diagnostic test in their first Science or Technology mathematics lecture in first year without prior warning.

The questions are marked correct or incorrect with no attempt marks given. Students are not allowed to use calculators during the test so consistencies in the conditions surrounding the test are maintained across the 10 years being analysed.

No changes have been made to the diagnostic test, in content or structure, since it was first introduced in 1997 to the close of this research. This allows for direct comparisons to be made across year groups, student type, etc. Students who get 19 out of 40 or below in the diagnostic test are deemed to be 'at risk' of failing service mathematics in UL. ${ }^{3}$ An 'at risk' student is advised to use the free mathematics support provided by the university as they are considered not to have the minimum basic mathematical skills necessary to pass their service mathematics modules (O’Donoghue 1999; Faulkner, Hannigan, and Fitzmaurice 2014). See Appendix for a sample of diagnostic test questions.

\subsection{The diagnostic test database}

All of the diagnostic test data gathered on Science and Technology students since 1997 have been stored in a large database. The database between 1998 and 2008 contains information on almost 6000 students. All students from the 1998 and 2008 cohorts contained in this database have been analysed for the purpose of the research outlined in this paper.

Over 60 items of information are detailed on each student, for example: how they performed on each individual question in the diagnostic test, each student's performance in each topic on the test (e.g. Algebra, Arithmetic), their mathematical performance prior to entering UL, their gender, the degree programme within which they are enrolled, etc. Information regarding whether a student is considered standard or nonstandard is also outlined:

A non-standard student is defined as a student who did not enter UL through the central application system used by all higher education institutions in Ireland. This cohort 
therefore consists of mature students (i.e. anyone over the age of 23 who has gained access to UL on the basis of an interview), non-national students and those who have completed previous certificate/diploma/degree and have used these as an entry point to UL.

(Faulkner, Hannigan, and Fitzmaurice 2014, 652)

Information on students' performance in the end-of-term service mathematics examination is also contained in the database. It should be highlighted that the service mathematics examinations which students sat at the end of the first semester in 2008 was very similar to that which previous cohorts of students have sat for the last 10 years (with the Technology mathematics examination being more predictable than the Science mathematics examination). The layout of the Technology mathematics paper has remained the same for the last 10 years and minimal changes have been made to the questions from year to year. For example, different functions and digits are introduced however the procedures used in each question remain the same. The Science mathematics paper has varied more from year to year with different lectures taking different approaches to asking questions and testing students' content knowledge.

\subsubsection{Entry routes: third-level education in Ireland}

Students in Ireland complete five to six years of second-level education which are broken up into the Junior Certificate programme, which takes three years to complete, and the Leaving Certificate programme, which takes two years to complete Faulkner, Hannigan, and Fitzmaurice 2014). Students may opt to take a transition year which takes place for one year in between the Junior Certificate and Leaving Certificate programmes. Students entering second-level education, at age 12-14 approximately, start by beginning the Junior Certificate programme which acts as a precursor to the Leaving Certificate programme which they tend to complete at the age of 17-19 approximately.

Mathematics in second-level education in Ireland is offered at three levels; Higher Level, Ordinary Level and Foundation Level. Students' performance in the Leaving Certificate programme can grant them direct entry to third-level education in Ireland. The centralised application system works by assigning a specific number of points to each grade received for up to six subjects in Leaving Certificate state examinations. For example, a student who got a Higher Level A1 grade is awarded 100 points, whereas an Ordinary Level A1 grade is worth 60 points. Each third-level programme has a minimum number of accumulated points which students must have to gain direct entry through the CAO system. For example, a student who wishes to gain direct entry through the Central Applications Offices (CAO) system to a third-level programme requiring 560 points could do this by getting 5 Higher Level A1 grades and 1 Ordinary Level A1 grade (Faulkner, Hannigan, and Fitzmaurice 2014). Many third-level programmes set a matriculation requirement (e.g. students must have English, Irish and four other Leaving Certificate subjects); however, the points requirements for a programme are generally determined by the interaction between the number of places available on a particular programme and the number of applicants to that programme in a specific academic year. The points requirement for third-level programmes can therefore vary from year to year.

\subsection{Declining standards in diagnostic test performance over time}

Previous research carried out on the UL database revealed significant change in the profile of students entering Science and Technology mathematics between 1998 and 2008 (Faulkner, Hannigan, and Gill 2010). As previously outlined there was a 
significant change in the percentage of non-standard students. There was an increase of 9.1 and 5.4 percentage points of non-standard students in Technology and Science mathematics, respectively. There was also a decrease in the percentage of students entering these programmes with Higher Level second-level mathematics of 7.8 percentage points and 17.4 percentage points in Science and Technology, respectively (Table 1) (Faulkner, Hannigan, and Gill 2010).

More recently, published research demonstrates that this declining trend has continued from 2008 to 2014 (Treacy and Faulkner 2015). Faulkner, Hannigan, and Gill (2010) found that the aforementioned changes to the student profile within these service mathematics groups was matched with an increase in the percentage of students considered to be 'at risk' of failing service mathematics according to the diagnostic test. In Technology mathematics the percentage of students considered to be 'at risk' increased from $32.8 \%$ in 1998 to $46.4 \%$ in 2008 and it went from $21.3 \%$ to $46.0 \%$ for Science mathematics students. A significant decline over time occurred for Science and Technological mathematics students in UL in the areas of arithmetic and algebra along with an increase in the variability of results $(p<.001)$. Faulkner, Hannigan, and Gill (2010) also concluded that the changing student profile within this service mathematics group was a major contributing factor to the large increases in the proportions of students considered to be 'at risk' of failing service mathematics in UL. A shift in student intake like this has been shown to affect overall mathematical performance in other institutions also such as Coventry University in the UK (Lawson 1997; Faulkner, Hannigan, and Gill 2010). The changing profile of this cohort of students and its contribution to the declining diagnostic test performance was the initial catalyst for the research detailed in this paper. An extensive examination of performance of standard and non-standard students is detailed in Section 4. The next section outlines the statistical methodology employed in this research.

\section{Research question, research hypothesis and statistical methodology}

\subsection{Research question}

How does the performance of non-standard students, with a particular focus on mature students, in a diagnostic mathematics test and an end-of-semester mathematics test compare with the performance of standard students (i.e. those coming directly from second-level education)?

\subsection{Research hypotheses}

It is hypothesised that standard students will outperform non-standard students, primarily comprising mature students, in the diagnostic test and that mature students will improve in their mathematics test performance over time but still not outperform standard students. This pattern is hypothesised by the authors as research has shown that traditionally non-standard students struggle with mathematics on entry to higher education (Golding and O'Donoghue 2005); however, they tend to improve over time due to adapting desirable learning approaches to learning mathematics (Gill and O’Donoghue 2007).

\subsection{Statistical methodology}

All of the data analysis carried out with this research was done using the statistical software package SPSS for Windows. The database used consisted of data on 5949 students in total. 
Descriptive statistics such as means, percentages, standard deviations and coefficient of variation were used to describe trends by year within the data. To examine if statistically significant differences existed between the means of two groups, independent samples $t$-tests were used. The equality of variances assumption was satisfied for all independent samples $t$-tests carried out. Statistically significant associations between the qualitative variables were determined using chi-squared tests and significant differences between the three or more means were determined using analysis of variance (ANOVA). A 5\% level of significance was used for all tests and no adjustment was made for multiple tests. Assumptions for all tests used were satisfied before the tests were carried out. The spread/dispersion of results was tested using the standard deviation and coefficient of variation (standard deviation $/$ mean $\times 100$ ). A significant difference between the variances of two groups was examined using Levene's test for equality of variances (Faulkner 2012; Faulkner, Hannigan, and Fitzmaurice 2014).

\section{Profile of non-standard students in UL and a comparison of their mathematical performance with standard students}

One of the most significant changes to the student profile within the lifespan of this research was the increase in non-standard students entering the services mathematics courses in question. This section details the breakdown of students within the non-standard student category and outlines a comparison of the performance of non-standard students and standard students in the two mathematics examinations in question, that is, the diagnostic test and service mathematics examinations.

\subsection{Profile of non-standard students in 2008}

As previously mentioned, non-standard students are made up of (i) mature students, that is, students who are 23 years of age or older, (ii) non-Irish national students, that is, students who have reached a certain standard of schooling in their own country and are deemed to be of a similar standard to Leaving Certificate students in Ireland and (iii) students with previous qualifications such as a diploma, degree or a certificate who are returning to college.

Within the 2008 non-standard group the following breakdown occurs:

- $40(71.4 \%)$ of the students are mature students, all of whom have no previous qualifications from UL, are over 23 and have not completed the Leaving Certificate in the last 5 years. Some mature students gain access to UL degree programmes through a 1-year intensive access course which consists of a variety of subjects depending on the students' choice of degree programme. Upon passing access course examinations and/or on the basis of an interview, mature students can gain places in degree programmes.

- $6(10.7 \%)$ are students who have gained entry to UL in 2008 based on their completion of a previous degree/diploma/certificate in a variety of third-level institutions around Ireland. The previous qualifications of these non-standard students range from engineering, industrial automation, automation technology and environmental science to areas of study which are likely to consist of less mathematics content such as sport and exercise science and archaeology. 
- The remaining $10(17.9 \%)$ students are made up of non-national students who have completed an alternative school leaving qualification to the Leaving Certificate in another country.

Grouping these students together may not be appropriate if they are found to be non-homogenous in terms of their diagnostic test scores and service mathematics performance. The students within the non-standard category may perform to different standards due to differences, for example, in years since study of formal mathematics, age or motivation levels. The investigation which is outlined in the following section offers some insight into whether the group are homogenous or not.

\subsection{Comparison of the mathematical performance of non-standard and standard students}

\subsubsection{Performance of non-standard students in the diagnostic test in 2008}

The figures mentioned in Section 4.1 highlight that mature students make up the majority of the non-standard cohort in UL; therefore, the majority of non-standard students have not studied mathematics for a number of years. This is evident in their diagnostic test results which can be seen in Figures 1 and 2. Non-standard students have mean diagnostic test scores (expressed as a percentage of correct answers out of 40 questions) below that of the standard student coming directly from Leaving Certificate. For both Science and Technological non-standard students, the vast majority, with the exception of a few outliers, are classified as being 'at risk' of failing their end-of-semester examinations. Of the 273 standard Technology

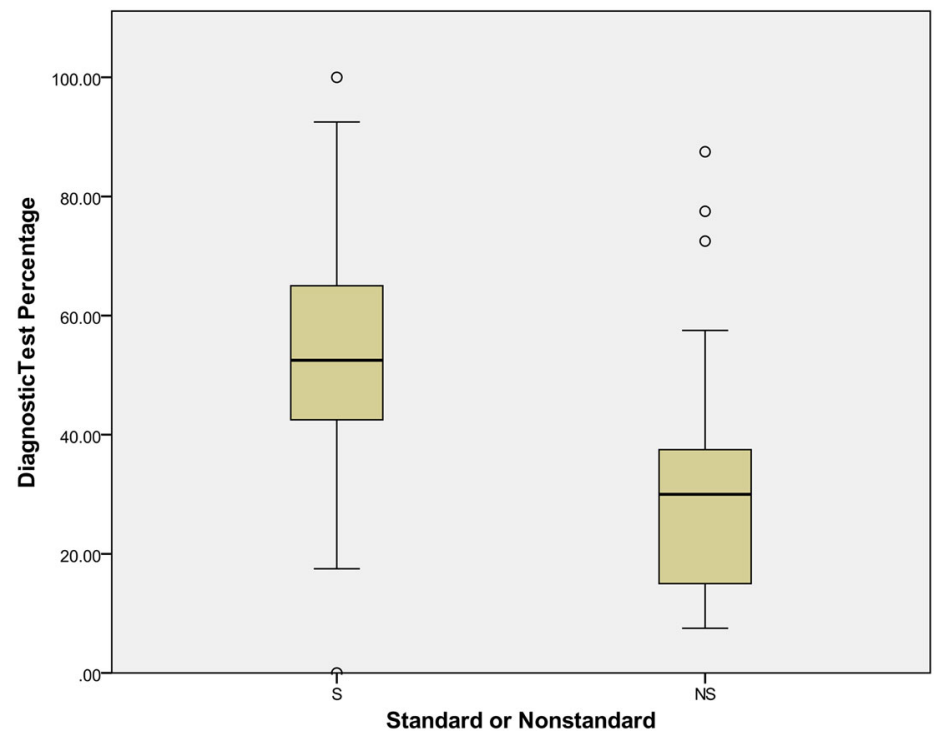

Figure 1. Comparison of diagnostic test performance for standard $(n=273)$ and non-standard $(n=30)$ Technology mathematics students in 2008.

Note: Standard students mean diagnostic test score: $53.1 \%(\mathrm{SD}=15.75)$ and non-standard students mean diagnostic test score: $32.5 \%(\mathrm{SD}=21.0)(p<.001)$. 


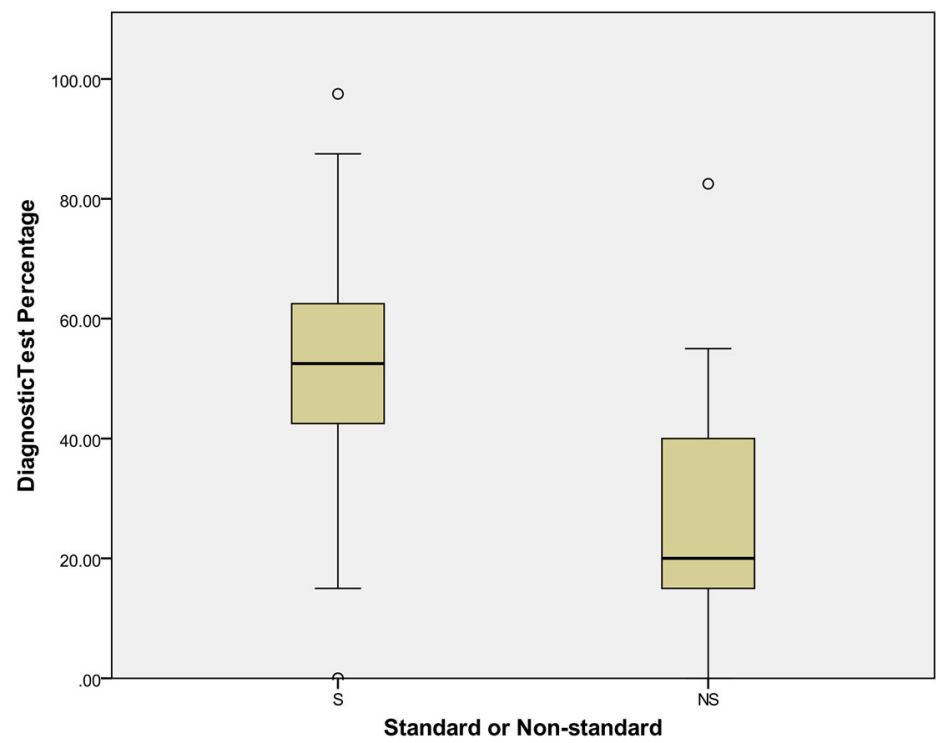

Figure 2. Comparison of diagnostic test performance for standard $(n=222)$ and non-standard $(n=15)$ Science mathematics students in 2008.

Note: Standard students mean diagnostic test score: $55.3 \%(\mathrm{SD}=16.5)$ and non-standard students mean diagnostic test score: $27.25 \%(\mathrm{SD}=21.0)(p<.001)$.

mathematics students who sat the diagnostic test $117(42.9 \%)$ were classified as being 'at risk' of failing Technology mathematics, while $23(76.7 \%)$ of the 30 non-standard Technology mathematics students who sat the diagnostic test were considered to be 'at risk' of failing. Similarly $96(43.2 \%)$ of the 222 standard Science mathematics students who sat the diagnostic test and $13(86.7 \%)$ of the 15 non-standard Science mathematics students who sat the diagnostic test were considered to be 'at risk' of failing service mathematics (Table 2). ${ }^{4}$ The box plots in Figures 1 and 2 highlight that non-standard students are mathematically less prepared entering UL than standard students.

Table 2. Number and percentage of students who were considered to be 'at risk' of failing service mathematics and those who failed service mathematics in Science and Technology mathematics in 2008 .

\begin{tabular}{cccccc}
\hline & \multicolumn{2}{c}{ Technology mathematics } & & \multicolumn{2}{c}{ Science mathematics } \\
\cline { 2 - 3 } \cline { 5 - 6 } & $\begin{array}{c}\text { 'At } \\
\text { risk' }\end{array}$ & $\begin{array}{c}\text { Failed service } \\
\text { mathematics }\end{array}$ & & $\begin{array}{c}\text { 'At } \\
\text { risk' }\end{array}$ & $\begin{array}{c}\text { Failed service } \\
\text { mathematics }\end{array}$ \\
& $\begin{array}{c}n \\
(\%)\end{array}$ & $\begin{array}{c}n \\
(\%)\end{array}$ & & $n$ & \\
& $1 \%)$ & & \\
& $(42.9)$ & $(24.7)$ & & $(43.2)$ & $(27.7)$ \\
Standard students & 23 & 10 & & 13 & 2 \\
Non-standard & $(76.7)$ & $(30.3)$ & & $(86.7)$ & $(11.8)$ \\
students & & & & &
\end{tabular}




\subsubsection{Performance of non-standard students in service mathematics examinations in 2008}

As was previously outlined a higher proportion of non-standard students are considered to be 'at risk' of failing service mathematics when compared to their standard counterparts in both Technology and Science mathematics. The non-standard students, however, have higher median performances than the standard students in service mathematics for both the Technology and Science cohorts (Figures 3 and 4). In spite of this pattern, the proportion of non-standard Technology students who failed their service mathematics examination is higher than that of the standard Technology students. However, it is lower than would be expected based on the analysis of the diagnostic test data as performance on the diagnostic test was found to have a statistically significant association with performance in service mathematics examinations (Faulkner, Hannigan, and Fitzmaurice 2014).

Seventy-eight (24.7\%) of the 316 standard Technology students who sat the endof-semester examination failed it while $10(30.3 \%)$ of the 33 non-standard Technology students who sat the end-of-semester examination failed. The opposite was the case, however, for the Science cohort as $74(27.7 \%)$ of the 267 standard students who sat the end-of-semester examination failed it compared to $2(11.8 \%)$ of the 17 nonstandard Science students who sat the end-of-semester examination (Table 2). ${ }^{5}$ Just like the Technology non-standard students, the Science non-standard students performed to a higher standard than would be expected based on their diagnostic test performance. These findings must be considered in light of the larger spread of results of the non-standard Technology students and the small number of nonstandard students in both the Technology and the Science mathematics cohorts in 2008.

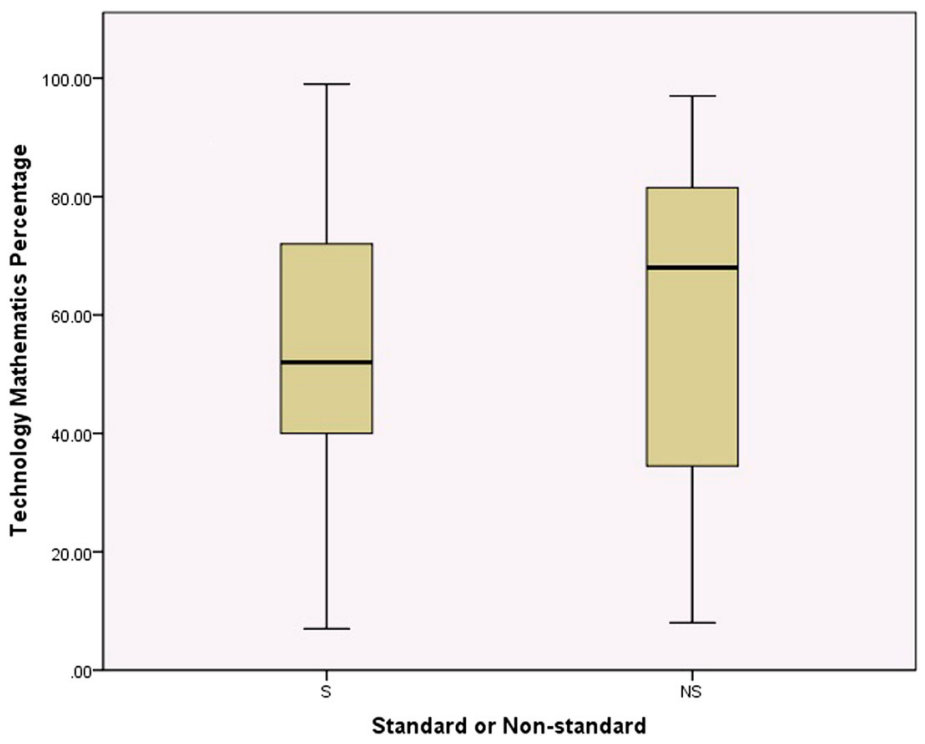

Figure 3. Comparison of Technology service mathematics performance for standard $(n=316)$ and non-standard $(n=33)$ students in 2008.

Note: Standard students mean service mathematics score: $53.9 \%(\mathrm{SD}=22.5)$ and non-standard students mean service mathematics score: $55.8 \%(\mathrm{SD}=29.5)(p<.001)$. 


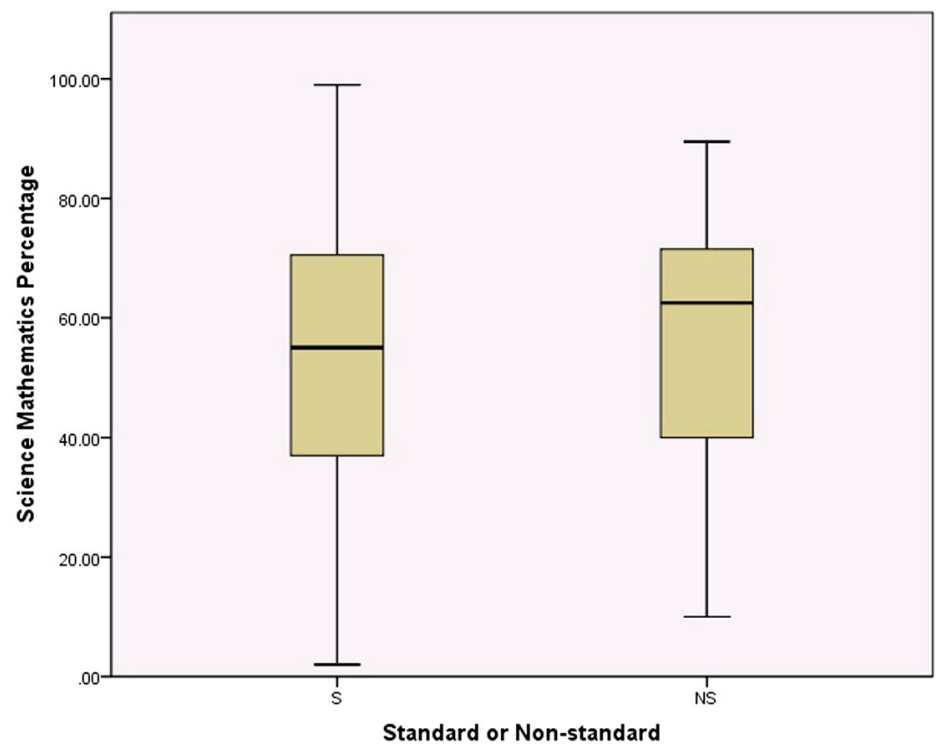

Figure 4. Comparison of Science service mathematics performance for standard $(n=267)$ and non-standard $(n=17)$ students in 2008.

Note: Standard students mean service mathematics score: $53.9 \%(\mathrm{SD}=22.2)$ and non-standard students mean service mathematics score: $59.0 \%(\mathrm{SD}=17.2)(p<.001)$.

The non-standard students, the majority of whom are mature students, are clearly less prepared mathematically than the standard students on entry to UL; however, they improve on average over the course of one semester. The fact that the nonstandard students improve so much compared to the standard students over time is unexpected as generally a student's diagnostic test performance is predictive of their service mathematics performance (Faulkner, Hannigan, and Fitzmaurice 2014). These findings therefore warrant further investigation.

\subsection{Standard and non-standard students' performance in the diagnostic test and service mathematics: further analysis}

4.3.1. Breakdown of non-standard students' performance in terms of three subcategories in 2008

In order to attempt to determine why non-standard students in 2008 have a lower mean performance in the diagnostic test, yet a higher mean performance in service mathematics compared to standard students, an analysis of non-standard students' performance by sub-category was undertaken. Therefore, the students were broken down into (1) mature students, (2) those who engaged in previous study and (3) international students (Table 3 ).

The aim of this investigation was to determine if one particular category of nonstandard student caused the mean to be particularly low in the diagnostic test or, alternatively, particularly high in service mathematics performance.

Each category within the non-standard group improved in their mean mathematics performance over time, particularly the mature students and the students who had engaged in previous study (Table 3). Initially $29(85.3 \%)$ of the mature students and 
Table 3. Mean performance and standard deviation of three sub-categories of non-standard students in the diagnostic test and service mathematics for Technology and Science students in 2008 (ANOVA $p<.001$ ).

\begin{tabular}{lccc}
\hline & $\begin{array}{c}\text { Mature } \\
\text { students }\end{array}$ & $\begin{array}{c}\text { Previous degree, } \\
\text { diploma, certificate }\end{array}$ & $\begin{array}{c}\text { International } \\
\text { students }\end{array}$ \\
\hline Mean diagnostic test result & 28.3 & 27.5 & 52.9 \\
expressed as a percentage (SD) & $(16.4)$ & $(8.9)$ & $(30.4)$ \\
& $n=34$ & $n=4$ & $n=7$ \\
Mean end-of-semester result & 54.9 & 61.7 & 61.9 \\
expressed as a percentage (SD) & $(27.9)$ & $(17.4)$ & $n=9$ \\
Percentage who passed service & $n=35$ & $n=6$ & 77.8 \\
$\quad$ mathematics & 71.4 & 100.0 & 10 \\
$\begin{array}{l}\text { Total number of students in each } \\
\text { category }\end{array}$ & 40 & 6 & \\
\hline
\end{tabular}

Note: 45/56 non-standard students sat the diagnostic test and 50/56 non-standard students sat the end-ofsemester examination.

$4(100 \%)$ of the students who had engaged in previous study were considered to be 'at risk' of failing service mathematics due to their diagnostic test performance. In spite of this, $25(71.4 \%)$ and $6(100 \%)$ of the mature students and students who engaged in previous study, respectively, were successful in their service mathematics examination. Why then do these sub-categories of students perform so poorly on entry to UL and improve so much over the course of the semester?

Mature students are sometimes said to be deficient in the basic skills needed for effective study in higher education (Richardson 1995). They have also, in general, studied significantly less mathematics than their younger counterparts (Relich, Way, and Martin 1994). They tend to perform poorly in mathematics diagnostic tests on entry to higher education when compared to the standard students due to numeracy problems (O’Donoghue 1995; O’Donoghue 1996; Kaye 2002; Maguire, Johnson, and Yasukawa 2002). Several reasons which have been suggested for this poor performance include:

- being out of practice with formal mathematics (O’Donoghue 1999);

- a lack of confidence in a formal education setting (Bowl 2001);

- weak mathematical backgrounds on entry to higher education (Golding and O’Donoghue 2005).

The initial challenges which mature students face, however, are likely to have been counteracted by their motivation to succeed. Mature students have been found to be more motivated by intrinsic goals than younger students in higher education (Pierce 1995; Forgasz 1996; Murphy and Roopchand 2003). In addition to this mature students tend to exhibit more desirable approaches to academic learning. They are less likely to adopt a surface learning approach in higher education than younger students. Younger students tend to acquire a surface learning approach to education due to their reliance on surface learning in their final years of secondary school. The prior life experiences of mature students, however, promote their tendency 
to adopt a deep learning approach over a surface learning approach (Richardson 1995; Jacobs and Newstead 2000; Smith 2002).

As well as their tendency to adopt more desirable approaches to academic learning, mature students have been found to more frequently avail of mathematics support services (Gill and O'Donoghue 2007). During the academic year 2008, UL provided support tutorials specifically for mature students in addition to one-to-one consultations with members of staff in the Mathematics Learning Centre (MLC). The MLC data in UL highlight the frequent use of the centre by mature students in all service mathematics courses. Data collected over the time period 2009-2011 found that typically over $50 \%$ of attendances to the MLC are by mature students (O'Keeffe 2011). Engagement with support services such as these have been found to have a positive impact on service mathematics grades for those students (Mac an Bhaird, Morgan, and O'Shea 2009; Gill, Mac an Bhaird, and Ni Fhlionn 2010). Their research gives an insight into mature students' progress with mathematics over the course of the semester.

In relation to the students who engaged in previous study, one of the possible reasons for their poor performance in the diagnostic test may, like mature students, be due to being out of practice with formal mathematics. Students within this category engaged in previous study such as a Sport and Leisure Diploma, Environmental Science Diploma and BA Archaeology. It is probable that these programmes did not have a strong mathematical content, if any. The move from studying mathematics at diploma level to degree level, for example, has been seen to be similar to the move between studying elementary mathematics to advanced mathematics. Tall (1991) describes this move as a significant transition from describing to defining, from convincing to proving which requires a cognitive reconstruction often found to cause great difficulty for students. The fact that students within this sub-category successfully completed previous academic programmes, however, suggests that they are motivated and willing to work hard despite the fact that their mathematical literacy is not strong at the beginning of the semester. One hundred per cent $(n=6)$ of the students who engaged in previous study were successful in service mathematics; however, the small numbers makes it difficult to draw a definite conclusion from these findings.

The international students perform to a much higher mean standard in the diagnostic test when compared to the other two sub-categories of non-standard students (Table 3). This is likely to be attributed to the fact that many of the students in this sub-category are entering UL after completing the equivalent of the Leaving Certificate in their respective countries. Their mathematics is therefore likely to have been practised in recent times when compared to the students within the other two sub-categories of non-standard students. The majority of the international students come from China with students also from Saudi Arabia, South Africa and Spain. The students in this sub-category also perform well in service mathematics with just $2(22.2 \%)$ of them failing. Again, the recent engagement with formal education and mathematics is likely to be a contributing factor to their success in service mathematics.

As mature students make up the majority of students in the non-standard category, their poor performance in the diagnostic test has the largest influence on the category's performance as a whole. The improvements of the mature students and those who have engaged in previous study along with the maintenance of the high performance from the international students resulted in the increase in the performance of the nonstandard students as a whole over time. 


\section{Conclusions and implications for policy and practice}

\subsection{Conclusions}

Between 1998 and 2008 there was an increase of 9.1 and 5.4 percentage points in the number of non-standard students in Technology and Science mathematics, respectively. The increase in non-standard students was matched with a decrease in the percentage of students entering service mathematics in UL with Higher Level Leaving Certificate mathematics. The extra students attracted to the degree programmes required to take Science and Technology mathematics are therefore students with Ordinary Level mathematics as pre-requisite knowledge and non-standard students who tend to perform to a lower basic mathematical standard as measured by the UL diagnostic test on entry to UL. The changing profile of Science and Technological mathematics students between 1998 and 2008 was found to be a major contributing factor to the declining standards in mathematical competency as measured by the UL diagnostic test of students entering UL (Faulkner, Hannigan, and Gill 2010; Faulkner, Hannigan, and Fitzmaurice 2014). A similar change in student intake also caused declining mathematics standards to occur in Coventry University (Lawson 1997). The findings of Barry and Chapman (2007) also state that performance in mathematics in third-level institutions has been shown to be better when students have Higher Level mathematics as pre-requisite knowledge.

The comparison of standard students' performance with non-standard students' performance revealed that non-standard students' diagnostic test score was below that of the standard students; however, their mean service mathematics performance was higher with a greater spread of results (however, a larger proportion of non-standard Technology students failed service mathematics when compared to standard Technology students). This finding was surprising as students' performance in the diagnostic test has been found to be predictive of their service mathematics examination performance (Faulkner, Hannigan, and Fitzmaurice 2014). This unexpected finding was found to be partially due to mature students and those who engaged in previous study improving in their mean mathematics performance over the course of the semester, with international students maintaining what was already a strong mathematical performance in the diagnostic test. Potential reasons examined for such improvements in mature students in particular can be summarised as follows:

- their motivation to succeed (Murphy and Roopchand 2003);

- their tendency to adopt desirable approaches to learning (Smith 2002);

- their frequent use of available mathematical support services (Gill and O’Donoghue 2007).

\subsection{Implications of findings for policy and practice}

The main findings revealed within this research surrounding mature students' ability to improve their basic mathematical skills so significantly over time raised several questions which could have implications for higher education institutions' policies and practices.

What are standard undergraduate students learning over the course of a semester? Despite the fact that the majority ( $80 \%$ approximately) of non-standard students are considered to be 'at risk' of failing service mathematics at the beginning of the term, a much smaller proportion of them actually fail $(30.3 \%$ and $11.8 \%$ in Technology and Science mathematics, respectively). Conversely, of the $42 \%$ of standard students 
considered to be 'at risk' of failing service mathematics, only $24.7 \%$ and $27.7 \%$ in Technology and Science mathematics, respectively, go on to fail. This possibly demonstrates the success of surface learning for passing examinations which has been discussed in the literature (Busato et al. 2000; Trockel, Barnes, and Egget 2000; Kuol et al. 2006; Hourigan and O'Donoghue 2007; Hyland 2011). The very fact that it is possible for students to improve in their basic mathematical performance so much over a short space of time, as evidenced by the mature students' performance, could lead to the question: Should we be insisting on higher standards and real engagement with the resources that already exist and are free of charge from standard undergraduate students? This paper provides one way of determining the likely mathematical performance of our students, and demonstrates how effective engagement with mathematics support over time could be; therefore it may be time to determine for certain if those in the 'at risk' category were to use the facilities available to them whether we would ensure higher standards of undergraduate output across the board. It would also ensure a better use of an existing funded mathematics support service which most higher education institutions in Ireland now provide and invest heavily in (O’Sullivan et al. 2014).

Examination and discussion surrounding the probable manner in which mature students learn, which has been examined in much literature before now (i.e. their tendency to use deep learning approaches) (Richardson 1995; Jacobs and Newstead 2000; Smith 2002), could be seen by those in mathematics education, and other disciplines, as a model through which undergraduate mathematics material should be dealt with. Further examination into mature students' learning styles in mathematics as compared to students entering third-level education directly from second-level education could provide explicit learning methods which lecturers could use to guide all students in their learning of mathematics. For example, in replacement of coursework which students could successfully complete through memorisation and routine and practice procedures alone, lecturers could incorporate mathematics problems and questions which insist on a demonstration/discussion of why the mathematics/mathematical procedures in question make sense and where they may be useful in a real-life context. This encouragement of a shift in learning styles could be incorporated into policy and practice in an attempt to improve students' engagement with mathematics, their understanding of mathematics and in turn their mathematical ability upon completion of their respective programmes.

The findings presented in this research touch on the varying needs of the students who enter undergraduate education in Ireland and abroad today. Over the last two decades we have seen a significant change in the profile of students entering undergraduate education with one of the most noted and obvious changes being the increase in mature students (OECD 1987; Gallagher, Richards, and Locke 1993; Clancy 1995; Lynch 1997; Central Statistics Office 2014). Most institutions have catered for this change quite well by providing necessary support systems (mathematics and otherwise) aimed to help retain the mature student body in the higher education system until successful completion of their programmes (Higher Education Authority 1995; Council of Europe 1996; Fleming et al. 2010). With the increase in the mature student body we may have somewhat forgotten about the increasing number of standard students, the majority of whom are made up of students whose academic and socio-economic backgrounds had traditionally deemed them less suitable for thirdlevel education when compared to their higher academically performing counterparts (Lynch and O' Riordan 1998; Higher Education Authority 2008; European 
Commission 2010; Higher Education Authority 2010). Although there are systems in place in many Irish institutions to try to prevent such students from dropping out (e.g. the first 7 weeks programmes in UL) it may be necessary to examine the student profile upon entry to higher education year on year and determine suitable pathways for each student type (e.g. non-standard; mature, standard; high academic achievement on entry, standard; low academic achievement on entry) to determine what support systems need to be in place in each case in an attempt to support each student in question appropriately.

Ireland's performance in mathematics in the most recent international Programme for International Student Assessment (PISA) study is currently ranked 20th out of 65 countries taking part. Ireland's performance in the literacy equivalent of the PISA study is 7 th out of 65 and in a Science context Ireland rank 15th out of 65 countries. Acknowledgement by those involved in mathematics education in Ireland of this evident shortfall in terms of mathematics performance, particularly when compared to performance in other areas, has led to the establishment of initiatives such as a new mathematics curriculum in second level aimed at improving understanding and performance in mathematics. In conjunction with this new initiative being introduced Irish students are being incentivised to take Leaving Certificate Higher Level mathematics as they are now awarded bonus CAO points for doing so. This research gives a longitudinal objective overview of students' mathematical performance in third-level education prior to these significant initiatives/changes being introduced; it will therefore be valuable to see what change, if any, occurs in the next 10 years as UL continue to administer this diagnostic test. This unique objective test is providing an extremely valuable means of analysing potential changes in students' basic mathematical skills over time with a view to best supporting improved standards in mathematics education.

\section{Funding}

This work was supported by the Mathematics Applications Consortium for Science and Industry.

\section{Notes}

1. A non-standard student is any student entering UL who has not come directly from secondlevel school in Ireland. Further details regarding what this constitutes will be outlined in Section 4.

2. Data on students gathered in 1997 have not been used as diagnostic testing was only carried out on Technology students; however, from 1998 both Technology and Science mathematics students were examined.

3. This figure was refined when discriminant analysis was carried out on the diagnostics test database (described in Section 2.3) after the analysis in this paper was carried out to someone being considered as 'at risk' if they receive $18 / 40$ or below in the diagnostic test (Faulkner 2012). The cut-off remains at this point now.

4. Note that 273/339 standard Technology students sat the diagnostic test in 2008 and 30/35 non-standard Technology students sat the diagnostic test in 2008; 222/282 standard Science students sat the diagnostic test in 2008 and 15/21 non-standard Science students sat the diagnostic test in 2008.

5. Note that 33/35 non-standard Technology students and 316/339 standard Technology students sat the end-of-term examination; 17/21 non-standard Science students and 267/282 of the standard Science students sat the end-of-term examination. 


\section{Notes on contributors}

Fiona Faulkner completed her Ph.D. in Mathematics Education in May 2012 from the University of Limerick. Currently she is Lecturer in Mathematics, Dublin Institute of Technology.

Ailish Hannigan is Associate Professor of Biomedical Statistics and Lecturer in Statistics, University of Limerick.

Dr Olivia Gill is Lecturer in Mathematics Education, University of Limerick.

\section{References}

Barry, S. I., and J. Chapman. 2007. "Predicting University Performance." Australia and New Zealand Industrial Applied Mathematics 49: 36-50.

Bowl, Marion. 2001. "Experiencing the Barriers: Non-Traditional Students Entering Higher Education." Research Papers in Education 16 (2): 141-160.

Busato, Vittorio V., Frans J. Prins, Jan J. Elshout, and Christiaan Hamaker. 2000. "Intellectual Ability, Learning Style, Personality, Achievement Motivation and Academic Success of Psychology Students in Higher Education.” Personality and Individual Differences 29 (6): 1057-1068.

Central Statistics Office. 2014. Labour Force Survey 1995. Dublin: Central Statistics Office.

Centre for Educational Research and Innovation and Organisation for Economic Cooperation and Development. 1987. Adults in Higher Education. Paris: CERI/OECD.

Clancy, P. 1995. Access to College: Patterns of Continuity and Change. Dublin: Higher Education Authority.

Council of Europe. 1996. Access to Higher Education: Access for Under-Represented Groups Vol. 2: Report on Western Europe" (by M. Woodrow and D. Crosier). Strasbourg: Council of Europe.

Edwards, P. 1995. "Some Mathematical Misconceptions on Entry to Higher Education." Teaching Mathematics and Its Applications 14: 23-27.

Edwards, P. 1996. Implementing Diagnostic Testing for Non-Specialist Mathematics Courses. London: OLF.

Engineering Council. 2002. "House of Commons Select Committee on Science and Technology.” Accessed January 2011. http://www.engc.org.uk/register_news/HOC.asp.

European Commission. 2010. Focus on Higher Education in Europe 2010: The Impact of the Bologna Process Education Audio-Visual and Cultural Agency. Brussels: Education, Audiovisual and Culture Executive Agency.

Faulkner, F. 2012. "An Analysis of Performance in Mathematics for Technology Undergraduates and an Investigation into Teaching Interventions for These Students." $\mathrm{PhD}$ diss., University of Limerick.

Faulkner, Fiona, Ailish Hannigan, and Olivia Fitzmaurice. 2014. "The Role of Prior Mathematical Experience in Predicting Mathematics Performance in Higher Education." International Journal of Mathematical Education in Science and Technology 45 (5): 648-667.

Faulkner, Fiona, Ailish Hannigan, and Olivia Gill. 2010. "Trends in the Mathematical Competency of University Entrants in Ireland by Leaving Certificate Mathematics Grade." Teaching Mathematics and Its Applications 29 (2): 76-93.

Fleming, Ted, Andrew Loxley, Aidan Kenny, and Fergal Finigan. 2010. "Where Next? A Study of Work and Life Experiences of Mature Students (Incl. Disadvantaged) in Three Higher Education Institutions". Combat Poverty Agency Working Paper No. 10/02. Available at SSRN: http://ssrn.com/abstract=1673763 or http://dx.doi.org/10.2139/ssrn.1673763.

Forgasz, H. J. 1996. "A Case for Mature-Age Mathematics Students." The Australian Mathematical Society Gazette 23 (5): 201-206.

Gallagher, A., N. Richards, and N. Locke. 1993. Mature Students in Higher Education: How Institutions Can Learn from Experience. London: Centre for Institutional Studies, University of East London.

Gill, O. 2006. "What Counts as Service Mathematics? An Investigation into the 'Mathematics Problem' in Ireland.” PhD diss., University of Limerick, Limerick. 
Gill, Olivia, Ciaran Mac an Bhaird, and Eabhnat Ni Fhlionn. 2010. "The Origins, Development and Evaluation of Mathematics Support Services." Irish Mathematical Society Bulletin 66 (2): $51-63$.

Gill, O., and J. O'Donoghue. 2007. "Justifying the Existence of Mathematics Learning Support: Measuring the Effectiveness of a Mathematics Learning Centre." In Proceedings of the Adults Learning Mathematics Conference, 154-164, University of Limerick, Limerick.

Gill, Olivia, John O’Donoghue, Fiona Faulkner, and Ailish Hannigan. 2010. "Trends in Performance of Science and Technology Students (1997-2008) in Ireland." International Journal of Mathematical Education in Science and Technology 41 (3): 323-339.

Golding, G., and J. O'Donoghue. 2005. "A Constructive Approach to Identifying the Mathematical Knowledge Gaps of Adults Learning Advanced Mathematics." In Proceedings of the First National Conference in Mathematics Education, 278-293, St. Patricks College, Dublin.

Higher Education Authority. 1995. Report of the Steering Committee on the Future Development of Higher Education. Dublin: Higher Education Authority.

Higher Education Authority. 2008. National Plan for Equity of Access to Higher Education 2008-2013. Dublin: Higher Education Authority.

Higher Education Authority. 2010. Euro Student Survey IV: Report on the Social and Living Conditions of Higher Education Students in Ireland 2009/2010. Dublin: Higher Education Authority.

Hourigan, M., and J. O'Donoghue. 2007. "Mathematical Under-Preparedness: The Influence of the Pre-Tertiary Mathematics Experience on Students' Ability to Make a Successful Transition to Tertiary Level Mathematics Courses in Ireland.” International Journal of Mathematical Education in Science and Technology 38 (4): 461-476.

Hunt, D. N., and D. A. Lawson. 1996. "Trends in Mathematical Competency of A-Level Students on Entry to University." Teaching Mathematics and Its Applications 15: 167-173.

Hyland, A. 2011. Entry into Higher Education in Ireland in the $21^{\text {st }}$ Century. Cork: Higher Education Authority and the National Council for Curriculum and Assessment.

Jacobs, P. A., and S. E. Newstead. 2000. "The Nature and Development of Student Motivation." British Journal of Educational Psychology 70 (2): 243-254.

Kaye, D. 2002. "Defining Numeracy." In Proceedings of the 9th International Conference on Adults Learning Mathematics (ALM-9), 102-106, London: Kings College.

Kuol, N., A. Risquez, M. Morley, and S. Moore. 2006. "Core Factors Influencing Academic Performance Negatively Among Early Undergraduates at the University of Limerick: The Role of Social Involvement." In Keeping Students at University: A Retention Debate at Third Level, edited by S. Moore, O. Carr, M. Crehan, J. Crowley, D. Flynn, P. Morgan, and P. Shannon, 59-68. Dublin: Interesource Group Publishing.

Lawson, Duncan. 1997. "What Can We Expect from A-Level Mathematics Students?" Teaching Mathematics and Its Applications 16 (4): 151-156.

Lynch, K. 1997. "A Profile of Mature Students in Higher Education and an Analysis of Equality Issues." In Mature Students in Higher Education, edited by R. Morris, 79-116. Cork: Higher Education Authority Equality.

Lynch, K., and C. O' Riordan. 1998. "Inequality in Higher Education: A Study of Class Barriers." British Journal of Sociology of Education 19 (4): 445-478.

Mac an Bhaird, C., T. Morgan, and A. O'Shea. 2009. "The Impact of the Mathematics Support Centre on the Grades of First Year Students at the National University of Ireland Maynooth." Teaching Mathematics and Its Applications 28 (3): 117-122.

Maguire, T., B. Johnson, and K. Yasukawa. 2002. "Policies and Pedagogies for Lifelong Numeracy: An International Collaborative Project." In Proceedings of the 9th International Conference on Adults Learning Mathematics (ALM-9), 107-115. London: Kings College.

Malcolm, R. K., and P. McCoy. 2007. "Evaluation of Numeracy Skills in First Year Pharmacy Undergraduates 1999-2005." Pharmacy Education: An International Journal for Pharmaceutical Education 7: 53-59.

Murphy, H., and N. Roopchand. 2003. "Intrinsic Motivation and Self-Esteem in Traditional and Mature Students at a Post-1992 University in the North-East of England." Educational Studies 29 (2-3): 243-259. 
O’Donoghue, J. 1995. "Assessing Numeracy." In Proceedings of the 2nd International Conference on Adults Learning Mathematics (ALM-2), 105-111. London: Goldsmiths University.

O'Donoghue, J. 1996. "Assessing Numeracy 2: The Pilot Phase." In Proceedings of the 3rd International Conference on Adults Learning Mathematics: A Research Forum (ALM-3), 79-91. London: Goldsmiths University.

O'Donoghue, J. 1999. An Intervention to Assist at Risk Students in Service Mathematics Courses at the University of Limerick. University of Limerick teaching fellowship scheme. Limerick: University of Limerick.

O'Keeffe, L. 2011. "Maths Learning Centre Report." Internal Report. University of Limerick.

O'Sullivan, C., C. Mac an Bhaird, O. Fitzmaurice, and E. Ni Fhloinn. 2014. An Irish Mathematics Learning Support Network (IMLSN) Report on Student Evaluation of Mathematics Learning Support: Insights from a Large Scale Multi-Institutional Survey. National Centre for Excellence in Maths and Science Teaching and Learning (NCEMSTL), University of Limerick, Limerick.

Pierce, R. 1995. Research on Mature-Age Students Returning to Study Mathematics at the Tertiary Level. Geelong: National Centre for Research and Development in Mathematics Education, Deakin University.

Relich, Joe, J. Way, and A. Martin. 1994. "Attitudes to Teaching Mathematics: Further Development of a Measurement Instrument." Mathematics Education Research Journal 6 (1): 56-69.

Richardson, J. T. E. 1995. "Mature Students in Higher Education II. An Investigation of Approaches to Studying and Academic Performance." Studies in Higher Education 20 (1): 5-17.

Sahlberg, P. 2012. Report on the International Review Panel on the Structure of Initial Teacher Education Provision in Ireland. Dublin: Department of Education and Skills.

Smith, J. 2002. "Learning Styles: Fashion Fad or Lever for Change? The Application of Learning Style Theory to Inclusive Curriculum Delivery." Innovations in Education and Teaching International 39 (1): 63-70.

Tall, D. 1991. Advanced Mathematical Thinking. Dordrecht: Kluwer Academic Publishers.

Tall, D., and M. R. Razali. 1993. "Diagnosing Students' Difficulties in Learning Mathematics.” International Journal for Mathematics Education in Science and Technology 24: 209-222.

Todd, K. L. 2001. "An Historical Study of the Correlation Between GCE Advanced Level Grades and the Subsequent Academic Performance of Well Qualified Students in a University Engineering Department." Mathematics Today 37: 152-156.

Treacy, P., and F. Faulkner. 2015. "Trends in Basic Mathematical Competencies of Beginning Undergraduates in Ireland, 2003-2013." International Journal of Mathematical Education in Science and Technology 46 (8): 1182-1196.

Trockel, M. T., M. D. Barnes, and D. L. Egget. 2000. "Health-related Variables and Academic Performance among First-Year College Students: Implications for Sleep and Other Behaviours.” Journal of American College Health 49 (3): 125-131. 
Appendix. The UL diagnostic test

\section{UNIVERSITY OF LIMERICK \\ DEPARTMENT OF MATHEMATICS AND STATISTICS \\ DIAGNOSTIC TEST}

\section{PURPOSE}

The purpose of this test is to ascertain whether there are gaps in your knowledge of basic mathematics A programme of extra voluntary tutorials is planned for students who need assistance in mathematics during this term.

\section{NOTE}

This assessment does not contribute in any way to your grade for this course

\section{INSTRUCTIONS}

Please fill in the details requested and proceed to answer questions.

Attempt each question and if you do not know how to do a question, simply tick the don't know box. There is no penalty. Calculators are not allowed.

TIME: 40 mins (approx)

Name

I.D. No

\section{UL Programme}

Please tick $(\checkmark)$ the appropriate grade:

\section{LC (Maths): Higher A1 $\square$ A2 $\square$ B1 $\square$ B2 $\square$ B3 $\square$ C1 $\square$ C2 $\square$ C3 D D1 D2 D3 Grade

$$
\text { Ordinary A1 } \square \text { A2 }
$$

Mature Students: Please enter grade in appropriate box

$$
\begin{aligned}
& \text { LC (Higher) } \square \\
& \text { Ordinary } \square
\end{aligned}
$$


20 F. Faulkner et al.

\section{ARITHMETIC 01 - 013}

1. Work out $-(-8)+(-3)$

Ans $\square$ Don't know

2. Write down the value of $10-8 \div 2+9$

Ans $\square$ Don't know

3. Work out: $\frac{1}{2}-\frac{1}{3}$

Ans $\square$ Don't know

4. Find the mean of the numbers $12,14,10$ Ans $\square$ Don't know

5. Work out: $\frac{2}{3} \times \frac{4}{5}$

Ans $\square$ Don't know

6. Find $25 \%$ of 500

Ans $\square$ Don't know

7. Write down the value of $3^{4}$.

Ans ㅁon't know

8. Write down the value of $8^{\frac{1}{3}}$.

Ans $\square$ Don't know

9. Write down the value of $\frac{1}{2^{-4}}$.

Ans $\square$ Don't know

10. If $x=10^{2}$ then write down the value of $\log x$. Ans $\square$ Don't know

11. If $\log x=5$ then write down the value of $\log \left(x^{2}\right)$.

Ans $\square$ Don't know

\section{ROUGH WORK}


12. Express 0.01234 in Scientific Notation.

Ans $\square$ Don't know

13. Divide 30 in the ratio $3: 2$

Ans $\square$ Don't know

\section{ALGEBRA 014-021}

14. Solve for $h: V=\pi r^{2} h$

Ans $\square$ Don't know

15. Evaluate $\mathrm{ab}+2 \mathrm{bc}-3 \mathrm{ac}$ when $a=3, b=-2$ and $c=4$.

Ans

$\square$ Don't know

16. Solve the equation: $3(x+2)-24=0$

Ans $\square$ Don't know

17. Solve for $x: x^{2}+x-6=0$

Ans $\square$ Don't know

18. Solve the set of equations:

$2 x+y=7$

$x+2 y=5$

Ans $\square$ Don't know

19. Write out $(x+3 y)(a-2 b)$ in an equivalent form without brackets.

Ans $\square$ Don't know

20. Solve for $x: \quad 3-6 x<21$

Ans $\square$ Don't know

21. Simplify $\frac{1}{x-1}-\frac{2}{x+1}$

Ans $\square$ Don't know 
22 F. Faulkner et al.

31. Sketch the line $y=3 x+2$ on the diagram.

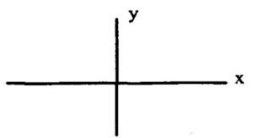

$\square$ Don't know

32. Sketch the curve $y=x^{2}+2$ on the diagram.

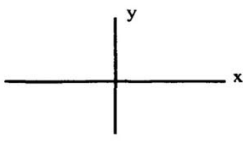

$\square$ Don't know

COMPLEX NUMBERS 033 - 034

33. If $z$ is the complex number $1+2 i$ find the modulus $|z|$.

Ans $\square$ Don't know

34. Simplify: $\frac{1+2 i}{2-3 i}$

Ans $\square$ Don't know

DIFFERENTIATION 035 - 037

35. If $y=2 x^{2}+3$ find $\frac{d y}{d x}$

Ans $\square$ Don't know 36. If $y=x \sin x$ find $\frac{d y}{d x}$

Ans $\square$ Don't know 37. If $y=e^{-2 x}$ find $\frac{d y}{d x}$ Ans $\square$ Don't know 
INTEGRATION 038 - 039

38. Evaluate $\int\left(x^{2}+2 x+3\right) d x$

Ans $\square$ Don't know

39. Evaluate $\int_{0}^{3} x^{2} d x$

Ans $\square$ Don't know

\section{MODELLING (SPECIAL OUESTION)}

40. The ESB charges domestic users $\mathfrak{£} 0.92$ per unit of electricity used. In addition each customer is also charged a standing charge of $£ 6.50$. Devise a formula for calculating the amount A of a customer's monthly bill when she uses $x$ units. (Ignore VAT).

Ans $\square$ Don't know

\section{ROUGH WORK}

